DOI 10.32370/IA_2019_01_14

\title{
Peculiarities of Teaching Quilling in Design in the Training of the Future Teacher of Fine, Applied and Decorative Arts
}

\author{
Kovalchuk Tatyana Petrovna \\ Senior Lecturer of the Department of Theory and Methodology of Decorative \\ Arts, graphic arts and graphic faculty of the State institution "South Ukrainian \\ National Pedagogical University named after K. D. Ushinsky"
}

\begin{abstract}
The article reveals role and place of quilling in formation of object space. The role of quilling as the main modeling method in creative workshops cannot be overestimated. Quilling is an intellectual asset of art modeling, which allows finding bright compositions. The value of quilling as the system of means of artistic expressiveness that provides ample opportunities for mastering and demonstration of the formal composition principles, is defined. It is declared that laws of the rhythmic organization of the form, principles of symmetry, dynamic basics in processing by plane paper folding or in formation of volume from paper, understanding of composition elements as the single constructive system, its combinatorial conversions, rows of program shaping, which integrate paper compositions into kinetic structures, allow to reveal all the diversity of composition opportunities for sheet materials using quilling as an example. It is emphasized that architectonics of paper constructions sets special sounding to the formal language of projects, latently influencing the world of real things created by artists, architects, sculptors, engineers. Paper compositions provide insight into a special logic of design from sheet materials; therefore, quilling develops not only artistic thinking, but also technical one. The study of basics of volumetric and spatial compositions by means of quilling combined with parallel mastering of methods and technologies of design from a sheet of paper is a fruitful basis in arts education of the graphics designers. Conclusions contain the arguments that the paper as one of the currently most available materials is a "tuning fork" of independent creative searches and experiments. Shapings from the paper stipulate the developed level of abstract thinking, which is necessary in artistic creativity and which is developed by the discipline of quilling.
\end{abstract}

Keywords: quilling, design, paper, decorative art.

Introduction. As a kind of decorative art, working with paper makes it possible to more actively develop aesthetic feelings and to add to the transformative work by the laws of beauty and harmony, to form the need for artistic creativity.

Recently, the importance of paper as a figurative material in decorative-applied, decorative, decorative art, design and architectural modeling has grown, due to the fact that paper is the most accessible art material, both in terms of simplicity in work and its value. Techniques of paperwork have more educational and educational capabilities. On an example of paper work, students learn a variety of visual skills. In the process of artistic and labor activity, they learn to analyze phenomena and objects of the surrounding world, they develop 
imaginations, arbitrary attention, compositional thinking, visual and image memory, a sense of rhythm, the beauty of the form, its spatial and structural features, perception of color and its transformation .

Using the properties of the paper and the methods of its processing makes it possible to make any shape of the object in a stylized form. Quite simple methods of working with paper are the basis for the manufacture of both planar and volumetric structures of any shape.

The degree of elaboration of the problem. During the 20-21st centuries, theorists and practitioners of design repeatedly addressed the topic of three-dimensional modeling and shaping from paper, paper plastic (paper plastic). Illustrative are the works of domestic authors B. Rakhmaninov, V. Koleichuk, A. Volkov, V. Gamayunova, A. Golubeva, V. Krakinovskaya, N. Kalmykova, A. Maksimova, M. Litvinov and others are of interest in this regard, articles in the methodological materials of design schools. Among foreign publications, one can mention the works of F. Zaer, who is the successor to the Bauhaus' traditions, the books by M. Chaitani, K. Nakazoy, developing the traditions of Japanese paper plastic and many others.

The works of these and many other authors present paper plastic as a multifaceted phenomenon. In some cases, paper features are studied in detail as a constructive material for packaging, in others as an area for comprehending the formal laws of composition, modeling techniques, and third as a tool for developing creative abilities.

Insufficiently lit parts of the problem. The fragmentation of the topics of publications and their dispersion in time do not allow to represent this area as a whole, in the diversity of its links with the project culture, creative laboratory and design methodology in design. There is a need not just to generalize the creative experience of artists, designers, historians and theorists, but also to clarify the methodological approaches of paper modeling in the educational process.

The purpose of the study is to determine the meaning, role and place of paper-making in the design culture.

The main content (research methodology). The specificity of working with paper involves mastering artistic means of creating decorative products, design, paper-making, design and other modeling techniques from paper and cardboard. Creativity in this area of artistic activity can develop successfully only if purposeful guidance from the teacher. 
Questions of the didactic provision of the process of studying this kind of art can be solved only by a teacher with a high level of methodological training.

In the process of learning must be formed the knowledge and skills in the field of stylization and generalization of real forms to figurative reproduction, the organization of the architectonics of flat and voluminous forms, their expressive harmony, which allows you to master: from the original sketch through the actual sketches to the design of the design in the material; methods and techniques of decorative plastic treatment of the surface of a sheet of paper; expressive means of forming products; compositional patterns of filling the surface of the sheet (the rhythmic organization of the image by way of repetition and grouping of elements, items of alternating elements, close in shape, color, size); the concept of the form and its main characteristics (proportions of the ratio of size, height and their influence on the figurative solution of the model, conditional structure and design); the basic concepts of spatial phenomena and their transmission on a plane and a bulk form in applied art, in design, and also to form knowledge and skills in the field of color (the notion of dark and light colors, nuanced and contrasting, local, one-tone, dispersed, familial Contrast, extra colors, associative mapping in color).

The main content (Discussion). During the 20th century, theorists and design practices have repeatedly turned to the topic of volumetric modeling and shaping of paper, paper-plastic (paper plastics). The works of many authors represent paper-plastic as a multifaceted phenomenon. In some cases, the peculiarities of paper as a constructive material for packaging are studied in detail, while in others as an area for comprehension of formal compositional laws, modeling techniques, and thirdly as a tool for developing creative abilities. Although books and manuals were published in the 70's and 80's, articles were published, as a rule, only isolated aspects of this topic were violated.

For example, such as the construction of models of stellate polyhedral, the creation of patterns for folded surfaces, training courses on the subject, the classification of methods of transformation of the plane. In general, the topic of paper-making in our country has not been appealing for a long time. The exception is propaganda of origami, which is essentially only a small part of the cultural and project experience in this field $[1 ; 2 ; 3]$.

Much of the modern materials that the designer deals with is flat materials. Of course, one should pay attention to the creative possibilities of paper-making plastics. According to 
Y. Vaserczuk thought, despite the fact that paper form formation has not been one decade, direct use of the term "paper" in the domestic literature does not occur. Traditionally, in the theory of design, the terms "paper-based plastic", "ornamental structure", "paper design", "structural space with guiding surfaces", "flat sheet transformation" were used. Of course, the term "paper-plastic" reflects both artistic and creative peculiarities, and the specifics of the genre itself, it is wider than simply "the use of folded or other patterns of paper in graphic design." With the introduction of this term it becomes possible historically to build the evolution of paper as a modeling material, the development of techniques and techniques of modeling, to show the continuity of the genre of experimental modeling. This term reflects the specifics of the author's approach to the study of composite, structural, structural and technological patterns [4].

The compositions themselves are not just samples of paper-making plastics, but also an analytical material that allows you to penetrate the foundations of form-forming patterns. This is a kind of modern "designer folklore", the secrets and techniques of which are transmitted directly in the process of living work and are form-forming luggage of artistic laboratories.

Paper-and-paper industry today is a promising area of design-shaping, which influences the development of a design culture. This area has an age-old experience, and, nevertheless, the form-creative potential of paper-and-paper industry is not exhausted.

The geometry of the paper form has gone through the formation of a scroll to a plane, from structured simple folds of sheets of paper in Shinto temples to developed combinator systems of modern origami, from experimental experiments in the constructivists environment to the intellectual base of formulating ideas in art laboratories that form the design culture of design. The geometry of a paper form is a multifaceted cultural phenomenon, whose role is the broadcasting of ideological settings that determine its formal qualities, structure, and function. Exploring the shape of the existence of a paper cloth, you can find rich historical and cultural material, as well as predict the role and place of paper in the future. Technology of paper production, having undergone a long path of evolution, allows today to receive a large number of grades of paper, which provide different types of operation.

The structure of paper linen determines the type and quality of paper constructions, its study allows to predict the aesthetic and structural features of the objects of paper-making. In 
the technology of industrial paper production, in the formulation of a paper sheet, which has a certain texture, format, texture, etc., the formal basis of the volume-spatial construction is laid.

Modern pulp and paper industry is a dynamically developing system, collections of varieties of paper are updated day by day, largely following the latest trends in the field of design, - as Pol Rend notes, At the same time, today is an actual appeal to the ancient method of manual casting of paper, whose purpose is to expand the perceptions of the very method of paper sheet. The paper and printing industry are often looking for impulses for innovations in their productions in an environment of independent form-making experiments, in turn, printing and paper development projects also expand the palette of paper-and-paper products.

World culture of paper-making has accumulated a considerable arsenal of methods and means of transformation of the paper plane, and folds, and cuts, and various types of gluing. Existing techniques of transformation of a paper cloth are largely borrowed from the printing industry, however, the potential of form-forming capabilities when working with a letter for it is still far from exhausted. By expanding the arsenal of methods of design, including "rough" technologies, by conducting a broad search for expressive means in paper-plastic, artists stimulate the development of paper form-forming in industrial environments [5].

Developed experimental activity in the field of paper-making allowed to accumulate a variety of methods and tools for plastic design. Paper constructions have a special logic of forming, which is based on the principles of sheet transformation. Proceeding from this logic, the construction of volume, the formation of tectonics of constructions, the finding of a special imagery in paper-making. Laconic, clear geometry, customary for paper designs, seems to impose a certain visual imprint on the objects of paper-making.

However, some kind of rigidity in the limitation of visual abilities, conventionality, lack of naturalism - the value of the quality of paper designs. Curvilinear shapes - bend the plane, the contour of complex curvature for flat shapes - extend the palette of expressiveness in paper-making.

Another important feature of paper constructions is that they allow you to form a hollow volume by creating a shell that meets the modern economically justifiable design principle with minimum cost, maximum effect. Paper-plastic is today a worthy alternative to classical sculpture, both in the system of artistic education and more widely. Plastic design 
today pays special attention to sheet materials and methods of their bulk-spatial transformation.

As told N. Reznichenko, paper-and-plastics as a system of means of artistic expressiveness provides extensive opportunities for the development and demonstration of the foundations of formal composition. The laws of rhythmic form organization, the principles of symmetry, the dynamic basis in the processing of folds of paper planes or in the formation of paper volume, understanding the composition of elements as a single constructive system, its combinatorial transformations, the series of programmatic shaping, combining paper compositions into kinetic structures, allow An example of paper-making plastics reveals all the diversity of compositional possibilities for sheet materials. Paper-plastic is an intellectual asset of artistic modeling, which allows you to find bright compositional solutions [6].

Of particular importance for the paper form is its connection with the graphics. However, such a connection is characteristic, rather, for the European papegoplastyki. In oriental culture of the development of structural organization of the paper plane is carried out through the motor skills of the hand, so the traditional folded structures of the origami have the patterns of folded in half a square of paper. An important difference between European paper and paper industry is also in the deep relationship between the author's drawing or graphic construction with the volume-spatial composition. Graphic drawing, broadcasted by volumetric means, lies at the heart of the author's conceptions of organizing the space of artists A. Rodchenko, V. Koleichuk, V. Gamayunova, B. Rachmaninov, A. Volkova.

In the contemporary design culture, the polarization of trends and stylistic trends is manifested in the field of paper-polish. Structural beginning comes from avant-garde geometry, and the free and emotional - also from the avant-garde and such traditions of paper-based plastics as paper molding, author's paper, etc. Knowledge of this experience allows you to creatively approach to the possibilities of paper-plastic in artistic shaping issues.

Today, paper forms - the basis for printing products, packaging, conceptual material, sketchy basis for the entire variety of projected products of graphic design. The combinatorial transformation of the paper plane and the image placed on it is an incentive to create new forms and formats of printing products, innovations in graphics, typography. Dynamic bases of paper constructions form the image of printed products, contributing to the development of interactivity of modern printing products. 
Conclusions. On the basis of the study, the following generalizations and conclusions can be made:

1. The development of paper shaping involves the developed level of abstract thinking, which is necessary in artistic creativity and which, in turn, is promoted during the mastery of paper-making. Paper-plastic in the context of contemporary art and design becomes a kind of "corps of instant response", a creative polygon.

2. Papers are today a promising direction of designer shaping, which influences the development of design culture and decorative and applied arts. There is an age-old experience in this area, and, nevertheless, the creative potential of paper-and-paper industry is not exhausted.

3. World culture of paper-and-paper has accumulated a significant arsenal of methods and means of transformation of the paper plane: it is folds, and cuts, and various types of gluing. Existing techniques of transformation of a paper cloth are largely borrowed from the printing industry, however, the potential of form-forming capabilities when working with a letter for it is still far from exhausted. By expanding the arsenal of methods of design, including "rough" technologies, by conducting a broad search for expressive means in paperplastic, artists stimulate the development of paper form-forming in industrial environments.

4. Paper-plastic is an intellectual asset of artistic modeling, which allows you to find bright compositional solutions.

5. The development of paper shaping involves the developed level of abstract thinking, which is necessary in artistic creativity and which, in turn, is advanced during the mastery of paper-plastic. Paper-plastic is a tuning-cartoon of a design culture; Having absorbed the experimental material of artistic thought, she becomes the bearer and keeper of many ideas. Studying the history of paper-making, we study the history of design thought.

Prospects for further research. We must be continue our research to study the methods of paper-making because the paper-based plastics is a tuning-cartoon of a design culture, incorporating the experimental material of artistic thought, it becomes a carrier and custodian of many ideas, and remained within the framework of creative laboratories.

\section{References}

1. Bozhko Yu.T. Osnovyi arkhitektoniki I kombinatoriki formoobrazovaniya. [Basics of architectonics and combinatorics of shape formation]. Kharkov. 1984. Vycha shkola. 
2. Volkotrub I.T. Osnovy kombinatoriki $v$ khudozhestvennom konstruirovanii. [Fundamentals of combinatorics in artistic design]. Kiyv. Vycha shkola. 1986.

3. Volkotrub I.T. Osnovy khudozhestvennogo konstruirovaniya. [Fundamentals of artistic design]. Kiyev. Vycha shkola. 1987.

4. Vaserczuk Y.A. Bumagoplastika v proyektnoy kul'ture dizayna [Paper agglutination in the design culture of design] Diss. ... kandidat iskusstvovedeniya : 17.00.06. Moskva. 2007. [in Russian].

5. Pol Rend Mysli o dizayne. [Thoughts on design]. Piter. 1947, re-publishing 2016. [in Russian].

6. Kovalchuk T.P., Reznichenko N.I. Vidy khudozhestvennoy raboty s bumagoy: naglyadno-metodicheskaya razrabotka. [Types of artistic work with paper: visual and methodological development]. Odessa. Astroprint. 1998. [in Ukraine].

7. Gagarin B.G. Konstruirovaniye iz bumagi: spravochnik. [Paper construction: a reference book]. Tachkent. Izdatel'stvo TCK KP Uzbekistana. 1988.

8. Iskusstvo bumagoplastiki v proektnoy cul'ture upakovki.V sb.: Dizayn, ergonomika, servis [The art of paper-plastic in the packaging design culture]. Moskva. VNIITE [in Russian]. 2007.

9. Nesterenko O.I. Kratkaya entsiklopediya dizayna. [Brief encyclopedia of design]. Molodaya gvardiya. Moskva. [in Russian]. 1994.

10. Rol' khudoczestvennogo konstruirovaniya iz bumagi v professional'noy podgotovke khudozhnikov-grafikov [The role of artistic design from paper in the professional training of graphic artists] Vestnik MGUPU. 2005 [in Russian].

11. Upakovka. Origami. Dzen. [Packaging. Origami. Zen]. Packaging R\&D. 2006.

12. Ustin Vitaliy. Kompozitsiya v dizayne: metodicheskie osnovy kompozitsionno khudoczestvennogo formoobrazovaniya v dizaynerskom tvorchestve. [Composition in Design: Methodical Foundations of Compositional and Art Formation in Design Work]. Astrel. [in Russian]. 2007.

13. Formirovaniye ob'emno-prostranstvennykh kaczestv peczatnoy produktsii sredstvami bumagoplastiki [Formation of volumetric-spatial qualities of printed matter by means of paper-plastic] Vestnik MGUPU. [in Russian]. 2006.

14. Holmyanskiy L.M. Maketirovaniye $i$ grafika $v$ protsesse khudozhestvennogo konstruirovaniya [Breadboarding and graphics in the process of artistic design]. Moskva. [in Russian]. 1978. 